\title{
Inhibition pattern of sulfamide-related compounds in binding to carbonic anhydrase isoforms I, II, VII, XII and XIV
}

\author{
Luciana Gavernet ${ }^{\mathrm{a}, *}$, José L. Gonzalez Funes ${ }^{\mathrm{a}}$, Pablo H. Palestro ${ }^{\mathrm{a}}$, Luis E. Bruno Blanch ${ }^{\mathrm{a}}$, \\ Guillermina L. Estiu ${ }^{\mathrm{b}, \mathrm{c}}$, Alfonso Maresca ${ }^{\mathrm{d}}$, Ivana Barrios ${ }^{\mathrm{a}}$, Claudiu T. Supuran ${ }^{\mathrm{d}}$ \\ ${ }^{a}$ Medicinal Chemistry, Department of Biological Sciences, Faculty of Exact Sciences, National University of La Plata, 47 and 115, La Plata B1900BJW, Argentina \\ ${ }^{\mathrm{b}}$ Department of Chemistry and Biochemistry, University of Notre Dame, Notre Dame, IN, USA \\ ${ }^{\mathrm{C}}$ Center for Rare and Neglected Diseases, University of Notre Dame, Notre Dame, IN, USA \\ ${ }^{\mathrm{d}}$ Università degli Studi di Firenze, Polo Scientifico, Laboratorio di Chimica Bioinorganica, Rm. 188, Via della Lastruccia 3, 50019 Sesto Fiorentino, Florence, Italy
}

\section{A R T I C L E I N F O}

\section{Article history}

Available online 29 November 2012

\section{Keywords:}

Carbonic anhydrase

Sulfamides

Docking

Molecular dynamic simulations

Inhibition pattern

\begin{abstract}
A B S T R A C T
A set of sulfamides and sulfamates were synthesized and tested against several isoforms of carbonic anhydrase: CA I, CA II, CA VII, CA XII and CA XIV. The biological assays showed a broad range of inhibitory activity, and interesting results were found for several compounds in terms of activity $\left(K_{\mathrm{i}}<1 \mu \mathrm{m}\right)$ and selectivity: some aromatic sulfamides are active against CA I, CA II and/or CA VII; while they are less active in CA XII and CA XIV. On the other hand, bulky sulfamides are selective to CA VII. To understand the origin of the different inhibitory activity against each isozyme we used molecular modeling techniques such as docking and molecular dynamic simulations.
\end{abstract}

(c) 2012 Elsevier Ltd. All rights reserved.

\section{Introduction}

The inhibition of Carbonic anhydrases (CAs) constitutes an attractive objective in medicinal chemistry. In addition to the traditional role of CA inhibitors as diuretic and antiglaucoma drugs, several clinical applications have been discovered. Among them, antiobesity, antiepileptic, antiinfective and antitumor activity can be mentioned. ${ }^{1-4}$

Despite the fact that sixteen $\alpha$-isozymes have been isolated in mammals with different subcellular localization and tissue distribution, all of them have a high degree of active site conservation. The active site comprises a $\mathrm{Zn}^{+2}$ ion coordinated by the imidazole rings of 3 histidine residues with the fourth position occupied by a water molecule at acidic $\mathrm{pH}(<8)$ and by a hydroxide ion at higher pH. ${ }^{1}$

In all the known isozymes, most of the inhibitors exert their effect by substituting the non-protein ligand in its interaction with the $\mathrm{Zn}^{+2}$ ion to generate the tetrahedral adduct. The metal ion is located in the bottom of a half hydrophilic and half hydrophobic cleft, through which the ligand reaches the active site. Typically, strong inhibition was achieved by sulfonamides, but in the last decade it was demonstrated that their bioisosteres sulfamides and sulfamates can exert the inhibitory action in the same manner. ${ }^{1,5,6}$ Recently we reported an investigation about the weaker inhibition pattern shown by sulfamides as compared to sulfamates

\footnotetext{
* Corresponding author. Tel.: +54 0221423 5333; fax: +54 02214223409 .

E-mail address: lgavernet@biol.unlp.edu.ar (L. Gavernet).
}

against CA II, and we interpreted this tendency using molecular modeling techniques. ${ }^{7}$ Following this research, we report here the inhibitory profile of a set of sulfamides and sulfamates against several CA isoforms. The compounds reported have been previously synthesized and tested in their anticonvulsant activity. ${ }^{8,9}$

It is well known that a number of CA inhibitors (CAIs) are/were clinically used to treat epilepsy (i.e. topiramate and acetazolamide among others). However, the relationship between CA inhibition and the anticonvulsant properties of these compounds cannot be directly assumed mainly due to three factors: (1) There is no complete information about the cellular basis of human epilepsy. It is known that events associated with the $\mathrm{pH}$ shifts, the increase in extracellular potassium concentration and the modification of the extracellular ionic environment are involved in the etiology of convulsive activity $;^{10-13}$ but the exact mechanisms that trigger seizures are not entirely elucidated. (2) The anticonvulsant drugs act through several mechanisms of action and most of them interact with more than one receptor to exert their action. ${ }^{14}$ Thus, targeting the inhibition of $\mathrm{CA}$ as the unique mechanism for the anticonvulsant action probably will not resolve the problem, but it will contribute to elucidate the importance of this enzyme in the development of seizures. (3) There are many isoforms of CA present in the brain and some of them (such as CAs II, VII and XIV), have been pointed out for their contributions to epileptiform activity. ${ }^{15-19}$

This research is focused in exploring the inhibition of sulfonamide bioisosteres on CA I and other four CNS-related CA isoforms: CA II, CA VII, CA XII and CA XIV. CA I, CA II and CA VII are cytosolic 
isozymes whereas CA XII and CA XIV are membrane-bound proteins with an extracellular enzyme active site. ${ }^{1}$ These environmental divergences, as well as the slightly structural differences in the active site region for each isozyme, provide the opportunity of designing new selective inhibitors. For example, it has been recently demonstrated that CA XII (and CA IX) represents an interesting target for anticancer drugs, particularly in diseases associated with hypoxic tumors. ${ }^{20}$ Hydrophilic glycosyl sulfonamide inhibitors of CA IX and CA XII have been designed to minimize the diffusion through lipid membranes and to promote the selective inhibition of transmembrane CAs. ${ }^{21}$ Similarly, this possibility has been explored through the synthesis of impermeant sulfonamides, which were designed to be positively charged in order to minimize their transport through the lipophilic membrane. ${ }^{22}$ On the other hand, the sulfamide analogue of topiramate (anticonvulsant drug) constitutes an interesting example of selectivity based on structural differences in the vicinity of the active site. Its weak binding to CA II has been attributed to the unfavorable Van der Waals contacts between the ligand and one residue of CA II (Ala65). ${ }^{4}$ This residue is present only in the CA II isozyme among many others isoforms in which the ligand shows good inhibitory properties.

Following this general idea, we decided to investigate the effects that may contribute to the differences observed in the activity of sulfamides/sulfamates in CA isozymes. Important interactions in the CA active sites were analyzed using molecular modeling techniques. To this end, a set of 23 compounds (Fig. 1) was prepared according to typical procedures, and their $K_{\mathrm{i}}$ values were determined for the CA isozymes (Table 1 ). The set includes sulfamates (compounds 1-2, 23), sulfamides substituted in one $\mathrm{N}$ atom (3-4) and their synthetic precursors (5-6), aryl, alkyl and cycloalkyl N,N'-disubsituted sulfamides (7-12), tetra-substituted sulfamides (13-15) and amino acid-derived sulfamides (16-22).

In order to investigate the effects that may contribute to the different binding affinity, we simulated the interaction of the compounds with CAs using docking and molecular dynamics simulations.

\section{Materials and methods}

\subsection{Synthesis of sulfamides and sulfamates}

The compounds presented here were obtained from different methodologies according to the nature and position of the subtituents of the sulfamide group. , 9,23 Their syntheses was previously reported and it was performed following the methodologies described below:

Symmetric N,N'-disubstituted sulfamides and tetra-substituted sulfamides were prepared in concordance with the typical procedures by condensation of an excess of amine with sulfuryl chloride (compounds 7 to 15). ${ }^{24-29}$ Similarly, N,N'-di-substituted aminoacid derived sulfamides 16-18 were prepared by reaction of the corresponding salts of amino esters with sulfuryl chloride in presence of triethylamine. ${ }^{30}$

Mono-substituted sulfamides (compounds 3-4) were synthesized following the standard method that involves the preparation of $\mathrm{N}$-alkoxycarbonyl sulfamides as intermediates of the<smiles>CCCCCCOS(N)(=O)=O</smiles>

1<smiles>CC(C)(C)OC(=O)NS(=O)(=O)NCc1ccccc1</smiles>

5<smiles>CCCCNS(=O)(=O)NCCCC</smiles>

9<smiles>CCCN(CCC)S(=O)(=O)N(CCC)CCC</smiles>

14<smiles>CCCC(CCC)COS(N)(=O)=O</smiles><smiles>CCCN(CCC)S(=O)(=O)NC(=O)OC(C)(C)C</smiles>

6<smiles>CCCNS(=O)(=O)NCCC</smiles>

10<smiles>CCCCN(CCCC)S(=O)(=O)N(CCCC)CCCC</smiles>

15<smiles>NS(=O)(=O)NCc1ccccc1</smiles>
3<smiles>O=S(=O)(NCc1ccccc1)NCc1ccccc1</smiles>

7<smiles>O=[SH](O)(NC1CC1)NC1CC1</smiles>

11<smiles>O=[SH](O)(NC1CCCCC1)NC1CCCCC1</smiles>

12<smiles>O=[SH](O)(NCCc1ccccc1)NCCc1ccccc1</smiles>

8<smiles>O=S(=O)(N1CCOCC1)N1CCOCC1</smiles>

13<smiles>COC(=O)CCNS(=O)(O)(O)NCCC(=O)OC</smiles>

16<smiles>COC(=O)C(C)NS(=O)(=O)NC(C)C(=O)OC</smiles>

17<smiles>CCCCNS(=O)(=O)NCCC(=O)OC</smiles><smiles>COC(=O)CNS(=O)(=O)NC(=O)OC(C)(C)C</smiles><smiles>CCCC(CCC)CN(C(=O)OC(C)(C)C)S(=O)(=O)NCCC(=O)OC</smiles><smiles>COC(=O)C(C)NS(=O)(=O)NC(=O)OC(C)(C)C</smiles><smiles>COC(=O)CCNS(=O)(=O)Oc1ccccc1O</smiles>

Figure 1. Chemical structures of the tested compounds. 
Table 1

Inhibition of CA isozymes hCA I, II, VII, XII and XIV by sulfamates/sulfamides (compounds 1-23)

\begin{tabular}{llllll}
\hline Compound & hCA I & hCA II & $K_{\mathrm{i}}^{\mathrm{a}}(\mu \mathrm{M})$ hCA VII & hCA XII & hCA XIV \\
\hline $\mathbf{1}$ & 3.66 & $2.82^{\mathrm{b}}$ & 0.70 & 0.73 & 0.82 \\
$\mathbf{2}$ & 2.98 & $1.92^{\mathrm{b}}$ & 4.30 & 0.89 & 0.86 \\
$\mathbf{3}$ & $0.13^{\mathrm{c}}$ & $0.12^{\mathrm{c}}$ & 0.30 & 0.94 & 0.84 \\
$\mathbf{4}$ & 24.9 & 60.3 & $>200$ & 3.53 & 7.10 \\
$\mathbf{5}$ & 8.84 & 161 & 0.17 & 0.89 & 40.4 \\
$\mathbf{6}$ & 6.88 & $>200$ & 0.32 & 0.91 & 52.6 \\
$\mathbf{7}$ & $>200$ & $0.65^{\mathrm{c}}$ & 0.38 & 81.5 & 35.5 \\
$\mathbf{8}$ & $>200$ & $>200^{\mathrm{b}}$ & $>200$ & $>200$ & $>200$ \\
$\mathbf{9}$ & 6.64 & $66.3^{\mathrm{b}}$ & 0.41 & 0.69 & 9.79 \\
$\mathbf{1 0}$ & 4.69 & $124^{\mathrm{b}}$ & $>200$ & $>200$ & $>200$ \\
$\mathbf{1 1}$ & $>200$ & $>200^{\mathrm{b}}$ & 0.16 & 0.77 & 8.79 \\
$\mathbf{1 2}$ & 6.64 & $100.1^{\mathrm{b}}$ & 0.32 & 0.70 & 9.94 \\
$\mathbf{1 3}$ & $>200$ & $135^{\mathrm{b}}$ & 0.47 & 9.10 & 48.8 \\
$\mathbf{1 4}$ & 9.35 & $>200^{\mathrm{b}}$ & $>200$ & $>200$ & $>200$ \\
$\mathbf{1 5}$ & $>200$ & $>200^{\mathrm{b}}$ & $>200$ & $>200$ & $>200$ \\
$\mathbf{1 6}$ & $>200$ & $>200$ & $>200$ & 70.8 & 8.40 \\
$\mathbf{1 7}$ & $>200$ & $>200$ & $>200$ & $>200$ & 7.66 \\
$\mathbf{1 8}$ & $>200$ & $>200$ & $>200$ & 73.0 & 7.97 \\
$\mathbf{1 9}$ & $>200$ & $>200$ & $>200$ & 61.2 & 8.37 \\
$\mathbf{2 0}$ & $>200$ & 55.7 & $>200$ & 56.3 & 5.92 \\
$\mathbf{2 1}$ & 62.2 & 41.1 & $>200$ & 65.4 & 8.09 \\
$\mathbf{2 2}$ & $>200$ & $>200$ & $>200$ & 54.5 & 5.38 \\
$\mathbf{2 3}$ & 88.7 & $>200$ & 68.7 & 65.0 & 8.53 \\
\hline & & 200 & & \\
\hline
\end{tabular}

a From three different assays, errors $\pm 10 \%$ of the reported value.

b Data taken from Ref. 7.

c Data taken from Ref. 5.

reaction. ${ }^{5,31}$ The reaction starts with the one-pot synthesis of $\mathrm{N}$-alkoxycarbonyl sulfamides (compounds $\mathbf{5}$ and $\mathbf{6}$ ) from chlorosulfonyl isocyanate, tert-butanol, and the corresponding amine in presence of triethylamine. The tert-butoxy carbonyl group was then removed via acidic hydrolysis. The $N$-alkoxycarbonyl sulfamides $\mathbf{5}$ and $\mathbf{6}$ obtained from the first step of the reaction were also tested against CAs. We considered that the measure of the inhibitory activity of these compounds is interesting to arrive to new structure-activity relationships. For the same reason we included the product of the reaction of chlorosulfonyl isocyanate, tert-butanol and the corresponding amino ester in presence of triethylamine (compounds $\mathbf{2 0}$ and 22). ${ }^{32}$

Compound $\mathbf{2 1}$ is the product of the alkylation reaction in Mitsunobu conditions ${ }^{33}$ of the reaction described before by using the methyl ester of B-Ala as reactant: Initially the chlorosulfonyl isocyanate and tert-butanol were added to the amino ester in presence of triethylamine; then the product (the $\mathrm{N}$-terbutoxycarbonyl sulfamide derivative) was allowed to react with the Mitsunobu tandem triphenylphosphine and diisopropylazodicarboxylate. ${ }^{32}$

Sulfamide 19 was obtained from the reaction of catechol sulfate (prepared with catechol and sulfuryl chloride) ${ }^{34}$ and the corresponding amino ester under controlled reaction conditions to yield a sulfamate ester derivative (compound 22); which reacts with buthylamine yield the nonsymmetric sulfamide. ${ }^{35}$

Compound $\mathbf{2 2}$ was also tested as a sulfamate derivative. The other sulfamates $\mathbf{1}$ and $\mathbf{2}$ were prepared by adding formic acid to chlorosulfonyl isocyanate to generate sulfamoyl chloride, ${ }^{36}$ which was then allowed to react in situ with the corresponding alcohol in basic conditions. ${ }^{36}$

\subsection{CA inhibition}

An Applied Photophysics stopped-flow instrument has been used for assaying the $\mathrm{CA}$ catalysed $\mathrm{CO}_{2}$ hydration activity. ${ }^{37}$ Phenol red (at a concentration of $0.2 \mathrm{mM}$ ) has been used as indicator, working at the maximum absorbance of $557 \mathrm{~nm}$, with $10-20 \mathrm{mM}$ Hepes ( $\mathrm{pH} 7.5$ ) as buffer, and $20 \mathrm{mM} \mathrm{Na}_{2} \mathrm{SO}_{4}$ for maintaining constant ionic strength, following the initial rates of the CA-catalyzed
$\mathrm{CO}_{2}$ hydration reaction for a period of $10-100 \mathrm{~s}$. The $\mathrm{CO}_{2}$ concentrations ranged from 1.7 to $17 \mathrm{mM}$ for the determination of the kinetic parameters and inhibition constants. For each inhibitor, at least six traces of the initial $5-10 \%$ of the reaction have been used for determining the initial velocity. The uncatalyzed rates were determined in the same manner and subtracted from the total observed rates. Stock solutions of inhibitor $(1 \mathrm{mM})$ were prepared in distilled-deionized water and dilutions up to $0.01 \mathrm{nM}$ were done thereafter with the assay buffer. Inhibitor and enzyme solutions were preincubated at room temperature for 15 min prior to assay, in order to allow for the formation of the E-I complex. The inhibition constants were obtained by non-linear least-squares methods using PRISM 3, whereas the kinetic parameters for the uninhibited enzymes were obtained from Lineweaver-Burk plots, as reported earlier, ${ }^{38-40}$ and represent the mean from at least three different determinations.

\subsection{Computational}

The binding of the compounds to CA I, CA II and CA VII, was analyzed using AutoDockTools 1.5 .0 and AutoDock 4.0 docking programs. ${ }^{41}$ The CA I starting protein was prepared from the crystal structure of the complex deposited by Christianson and coworkers (PDB code 2NN7). ${ }^{42}$ For CA II we used the $0.99 \AA$ resolution crystal structure of the CA II-sulfonamide complex (2FOU), ${ }^{43}$ as previously done when studying CA II sulfamide inhibition. ${ }^{7}$ We also modeled the conformational mobility of the side chain of His64 residue in the docking, which is likely associated with its role as a proton shuttle in catalysis. ${ }^{44}$ To this end, the docking was performed with the two different 'in' and 'out' conformations ${ }^{44}$ of His64 for CA II (Fig. S1). The out conformation was taken from the experimental structure (PDB code 2FOU), whereas the 'in' conformations were obtained from snapshots of molecular dynamics simulations (MD) for CA II (see below).

CA VII was prepared from the complex provided by Opperman et al (PDB code 3MDZ). ${ }^{45}$ Similarly to CA II, both 'in' and 'out' conformations of His64 were considered. In this case, Opperman et al distinguished the alternative conformations for the residue in the X-ray experiment (Fig. S1), and we were able to prepare both conformations from the experimental data.

In all cases, the crystallographic water molecules, the ligand, and any cocrystallized molecule/ion were stripped. Hydrogen atoms were added using the leap module of AMBER $11 .{ }^{46}$ Special attention was given to the protonation state of the $\mathrm{Zn}$-bound His residues of the actives site, which were defined as two histidines type Hid and one histidine type Hie in all the isozymes.

The structures of sulfamides and sulfamates were docked in their deprotonated form, since it is believed that these compounds coordinate to the active site as negative species. The anions of mono-substituted structures 1-4 were prepared by removing one $\mathrm{H}$ atom of the $\mathrm{NH}_{2}$ group. For $\mathrm{N}, \mathrm{N}^{\prime}$-di-substituted sulfamide $\mathbf{5}$ two different deprotonated forms can be constructed. Both anions were considered, and the data associated with the most stable complex (lower binding energy) is reported. Exceptions were compound 13-15 bearing no $\mathrm{H}$ attached to the binding $\mathrm{N}$. They were docked in their neutral form.

We used the default Autodock parameters for all the variables but the charges of the ligands, for which AM1-BCC charges were calculated using quacpac. ${ }^{47}$ This was found to perform better than the default Gasteiger charges in the CA II docking. ${ }^{7}$

The structures were docked using the Lamarckian genetic algorithm (LGA) in the 'docking active site', defined through a grid centered on the CG1 atom of Val59 residue for CA I, the ND2 atom of Asn67 residue for CA II and the ND2 atom of Asn64 for CA VII. In all isozymes we used 60,50 , and 60 grid points in $\mathrm{X}, \mathrm{Y}, \mathrm{Z}$ dimensions respectively, with the default grid spacing $(0.375 \AA)$; and 
performed 50 docking runs. The docking active site was treated as a rigid molecule and the ligands as flexible, that is, all non-ring torsions were considered active.

MD simulations were carried out for compound $\mathbf{1 1}$ in CA II and CA VII, using the PMEMD version included in the AMBER11 suite of programs ${ }^{46}$ after careful relaxation of the system using minimization and equilibration protocols. The conformations predicted by Autodock for the CA II /11 and CA VII/11 complexes were used as starting points for MD simulations. In both complexes His64 was selected in the 'out' conformation.

The initial geometries were minimized (1000 cycles for the water molecules followed by 2500 cycles for the entire systems). After a 20 ps NTV equilibration period with a weak restraint $\left(10 \mathrm{kcal} / \mathrm{mol} \AA^{2}\right)$ for the complex and a NTP 200 ps without restraint, production runs larger than 12 ns were computed for each complex, for the coordinates saved every 1000 time steps.

The ionizable residues were set to their normal ionization states at $\mathrm{pH} \mathrm{7,} \mathrm{except} \mathrm{for} \mathrm{the} \mathrm{His} \mathrm{residues} \mathrm{coordinating} \mathrm{the} \mathrm{Zn}$ metallocenter, which were modeled as Hid94, Hid96, and Hie119 (numbers relative to CA II). The protein atoms as well as all the water molecules of the crystal structure were surrounded by a periodic box of TIP3P32 water molecules that extended $10 \AA$ from the protein. Counterions were placed by LEaP26 to neutralize the system. The ff03 version of the all-atom AMBER force field was used to model the protein, and the GAFF force field was used for the organic ligand. ${ }^{48}$ Atom-centered partial charges were derived by using the AMBER antechamber program (restrained electrostatic potential [RESP] methodology), ${ }^{49,50}$ after geometry optimization at the B3LYP/6-31G** level. $^{51}$

As in previous investigations, ${ }^{7}$ nonstandard force fields have been derived for the $\mathrm{Zn}$ active site by means of geometry minimization (B3LYP/6-31G $\left.{ }^{* *}, \mathrm{G03}\right){ }^{52}$ followed by calculation of the second derivatives and RESP charges for the active site supermolecule defined by three His residues, the $\mathrm{Zn}$ ion, and the sulfamide ligand.

During the simulation, the 'out' conformation of His64 side chain changes to 'in' for CA II complex. Snapshots of this new conformation were captured and used to perform a new docking simulation with compounds 1-7 and 9-13.

The MD simulation of the compound 7-CA II complex is also mentioned in this research. We are using the results of previous investigations, whose computational details are given in Ref. 7.

\section{Results and discussion}

Table 1 reports the biological activity determined for the compounds shown in Figure 1. A broad range of inhibitory activities were observed for the compounds of the set. A weak binding $\left(K_{\mathrm{i}}\right.$ $>1 \mu \mathrm{M}$ ) was observed for amino acid-derived compounds 16-23 against all the tested isoforms. This can be explained by the polar nature of the substituents, which cannot make lipophilic stabilizing interactions with residues in the active site pocket, or by the effect of sizeable substituents on the $\mathrm{N}$ atom responsible for the coordination with the $\mathrm{Zn}$. It has been previously discussed that the replacement of $\mathrm{H}$ atoms of the coordinating $\mathrm{N}$ atom by alkyl (or aryl) substituents impairs the activity of single substituted sulfamides analogs in CA II. ${ }^{7}$ In the same line, bulky tetra-substituted sulfamides 14-15 as well as compound 8 were inactive against all the tested isozymes. Compound 13, being also tetra-substituted, shows selectivity against CA VII.

On the other hand, interesting results were found for the rest of the compounds from the set in terms of activity $\left(K_{\mathrm{i}}<1 \mu \mathrm{m}\right)$ and selectivity. Compound 3 measured $K_{\mathrm{i}}$ shows it a promising, with a value in the nanomolar range making it the most active of the series for CA I and CA II.
The weak inhibitory activity found in CA I compared with other isoforms was expected: The active site cavity of CA I is smaller than other isozymes, due to the presence of two characteristic His residues (His200 and His67) that are no conserved in other isoforms (Fig. 2).

For the case of CA II, derivatives bearing benzyl substituents 3 and $\mathbf{7}$ are the most promising inhibitors. As stated in previous investigations, we have found good CA II affinity with these aromatic compounds, and the origin of their inhibition has been analyzed earlier by means of molecular modeling techniques. ${ }^{7}$ The modeling has found favorable pi-stacking interactions between the phenyl rings and aromatic residues that can certainly contribute to the enhancement of activity. ${ }^{7}$ Structure $\mathbf{5}$ also has a benzyl substituent, but it is 247 times less active than 7 and 1341 times less active than 3, what can be attributed to the negative steric hindrance originated by the Boc-subtituent (see Section 3.1).

No good inhibition pattern was found against CA XII and CA XIV, for which the best compounds have $K_{\mathrm{i}}$ near the $\mu \mathrm{M}$ value. Conversely, a larger number of structures were found active in CA VII (brain-specific isoform). Several $\mathrm{N}, \mathrm{N}^{\prime}$-di-subsituted sulfamides (such as $\mathbf{5}$ and $\mathbf{6}$ ) show good inhibitory activity (in the range of $0.2-0.5 \mu \mathrm{M}$ ) against this isozyme. Additionally, aromatic and aliphatic compounds (i.e. 7 and $\mathbf{9}$ ) present a comparable inhibitory profile in CA VII. In order to gain insight into the facts that might be relevant for the binding, we investigated in some detail the different effects that can contribute to the trend observed in the inhibitory activity by means of molecular modeling approaches.

\subsection{Molecular modeling analysis}

We simulated the binding modes of compounds 1-7 and 9-13 against isozymes I, II and VII, since the other complexes did not show good inhibitory activity. Docking scores for isozymes I, II and VII are given in Table 2. They point to compound $\mathbf{3}$ as the most active one against CA I. Figure 2 shows the docking conformation found for the CA I-3 complex. The deprotonated N interacts with the $\mathrm{Zn}$ atom of the enzyme. This interaction is reinforced by two $\mathrm{H}$ bond interactions comprising the backbone $\mathrm{N}$ and carbonyl $\mathrm{O}$ atoms of the Thr196 residue with the $\mathrm{O}$ and the amide $\mathrm{H}$ atom of the sulfamide group, respectively (Fig. 2). These hydrogen bond interactions were previously reported for the experimental complex of CA I and a benzene sulfonamide derivative (PDB code 2NN7). The measured distance between the amine $\mathrm{N}$ atom of the sulfonamide and the Thr196 OG atom in the experimental structure is almost the same that the one found for compound $\mathbf{3}$ in complex with CA I (2.68A vs. 2.63A, respectively, Fig. 2); whereas the distance between the backbone $\mathrm{N}$ atom of Thr196 and the sulfomanide $\mathrm{O}$ atom of the ligand is very close to experiment (2.87A for the sulfonamide and $2.92 \mathrm{~A}$ for compound 3 ).

The interaction of the sulfamides with the Thr residues close to the active site was previously described for the complexes of mono-substituted sulfamides and the CA II isoform. ${ }^{7}$ In CA II, two consecutive Thr residues (Thr199 and Thr200) close to the active site stabilize the coordination of the sulfamide end of the ligands with the $\mathrm{Zn}$ atom through similar $\mathrm{H}$-bond interactions: the $\mathrm{NH}$ and OG atoms of the Thr residues acts as hydrogen donors/acceptors of the $\mathrm{O}$ and the $\mathrm{NH}$ atom of the sulfamides. ${ }^{7}$

In addition to the previously described interactions, docking studies show the aromatic scaffold of compound $\mathbf{3}$ oriented in a way that can stabilize a pi-stacking interaction with the Phe88 residue in CA I (Fig. 2). This effect, together with the small size and the mono-substitution of the molecule (that minimize the negative steric effects in this small active site relative to other CAs) can explain the better inhibitory activity of compound $\mathbf{3}$ against CA I in contrast to the other structures of the set. 


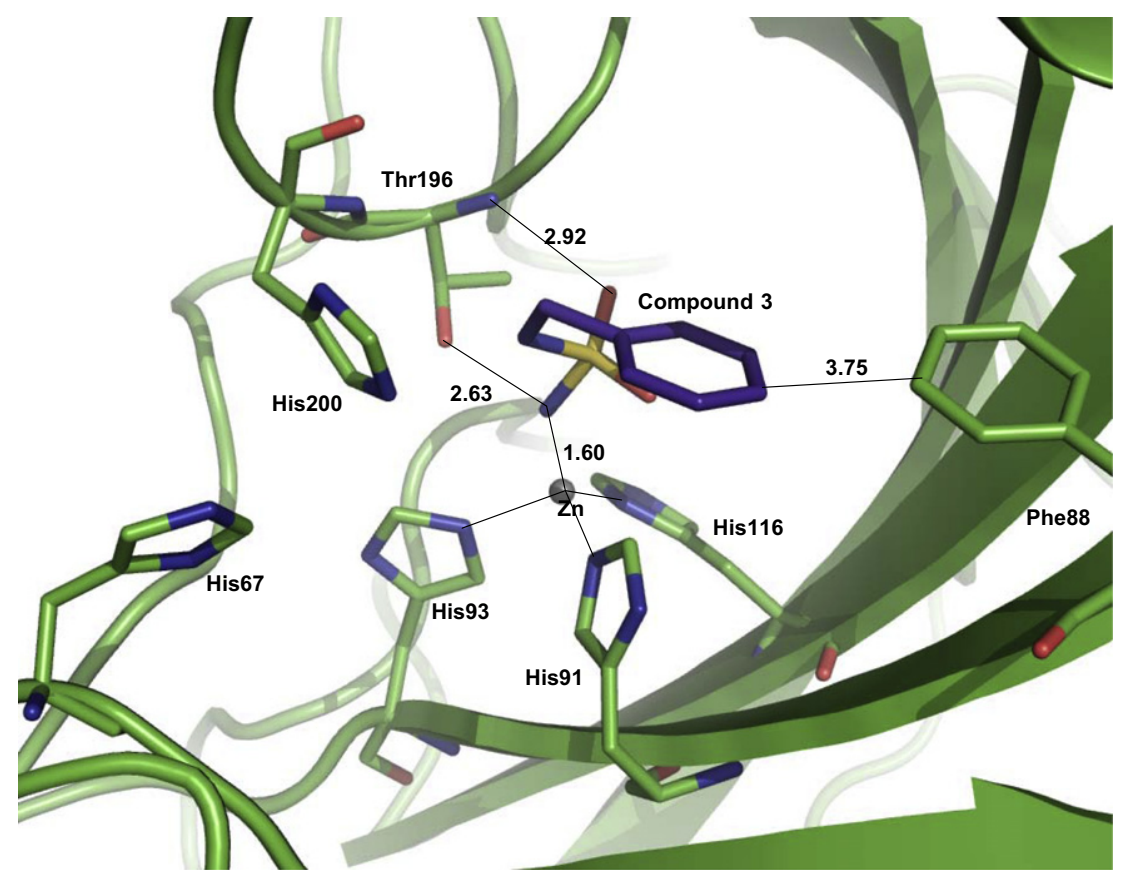

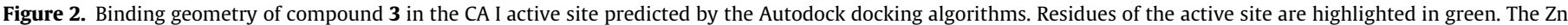
atom is represented in gray as a nonbonded sphere. The carbon atoms of compound $\mathbf{3}$ are highlighted in purple. Values of the relevant distances are given in $\AA$.

Table 2

Docking scores of sulfamides and sulfamates from docking against CA I, CAII and CA VII

\begin{tabular}{|c|c|c|c|c|c|c|}
\hline Compound & $K_{\mathrm{i}}$ & CAI docking score & $K_{\mathrm{i}}$ & CAII docking score & $K_{\mathrm{i}}$ & CAVII docking score \\
\hline 1 & 3.66 & -5.88 & 2.82 & -6.43 (in) & 0.7 & -6.35 (out) \\
\hline 2 & 2.98 & -6.14 & 1.92 & -6.9 (in) & 4.3 & -6.56 (out) \\
\hline 3 & 0.13 & -6.64 & 0.12 & -8.08 (in) & 0.3 & -6.64 (out) \\
\hline 4 & 24.9 & -5.97 & 60.3 & -6.42 (out) & $>200$ & -5.85 (out) \\
\hline 5 & 8.84 & -3.77 & 161 & -6.29 (in) & 0.17 & -5.70 (out) \\
\hline 6 & 6.88 & NA & $>200$ & $\mathrm{NA}$ & 0.32 & $\mathrm{NA}$ \\
\hline 7 & $>200$ & -6.07 & 0.65 & -8.03 (in) & 0.38 & -6.65 (out) \\
\hline 9 & $>200$ & -5.4 & 66.3 & -4.87 (out) & 0.41 & -5.43 (out) \\
\hline 10 & $>200$ & -4.82 & 124 & -5.37 (out) & $>200$ & -5.84 (out) \\
\hline 11 & 6.64 & -3.34 & $>200$ & -4.11 (out) & 0.16 & -5.62 (out) \\
\hline 12 & $>200$ & NA & 100.1 & NA & 0.32 & NA \\
\hline 13 & 9.35 & NA & 135 & NA & 0.47 & NA \\
\hline
\end{tabular}

For CA II and CA VII, the best score between the 'in' and 'out' conformations is reported and the conformation shown between brackets.

NA: not bound conformation was achieved in the docking process.

Regarding CA II, the scores are able to discriminate between the most active compounds 3 and 7. As explained in the experimental section, we performed docking experiments using two different conformations of the His64 residue of CA II. The best scores for these two most active sulfamides were obtained using the 'in' conformation. The origin of the activity of compounds $\mathbf{3}$ and $\mathbf{7}$ has been previously analyzed for the out conformation of CA II, which is the one found in the experimental structure of the enzyme (PDB code $2 \mathrm{FOU}){ }^{7}$ The ligand 3 interacts in both cases with Thr198 and Thr199, but the active site is smaller for the 'in' conformation of His64. The benzyl ring adopts a different conformation in order to fit in the smaller site, interacting with the lipophilic cleft of the enzyme, especially with the Leu197 residue (Fig. 3). The lack of interaction of compound 3 with His64 is counterbalanced with the favorable lipophilic interaction with Leu197 and Val144, as well a pi-stacking interaction between the phenyl ring of the ligand and His119.

Despite the negative effect caused by disubstitution in compound 7, it reinforces its binding through a lipophilic interaction with Leu197 and a second pi-stacking (T-shape) between the other benzyl ring and Phe131, which are responsible for the higher activity than the other di-substituted ligands. ${ }^{7}$ These interactions also became evident after 12 ns molecular dynamic simulations (Fig. 4). Phe131 is a non conserved residue that is present in CA II and CA VII (the isozymes where compound $\mathbf{7}$ is active), and it is replaced by Ala in CA XII and by Leu in CA I and CA XIV.

The previously described stabilizing interactions are not easily established for compound 8. Although with a similar scaffold as compound 7, the additional methylene group increases the size of the compounds precluding the fitting in the active site pocket. The superimposition of the docking poses for compounds $\mathbf{7}$ and $\mathbf{8}$ in CA II (Fig. 5) shows that compound $\mathbf{8}$ severely distorts, adopting a conformation that are higher in the energy than the more stable one and increasing the total energy of the CAII-compound 8 complex. According to the results of the docking, compound $\mathbf{7}$ defines the maximum length of the aryl-alkyl substitution compatible with the fitting in the CAII active site pocket. Similar explanation can be derived from the docking of compounds 7 and 8 in CA VII (Fig. S2).

The influence of the solvent in CA binding has been previously discussed. ${ }^{7}$ Diffusion of water molecules to the active site were detected and reported for compound 3 in CA II. ${ }^{7}$ In the case of 


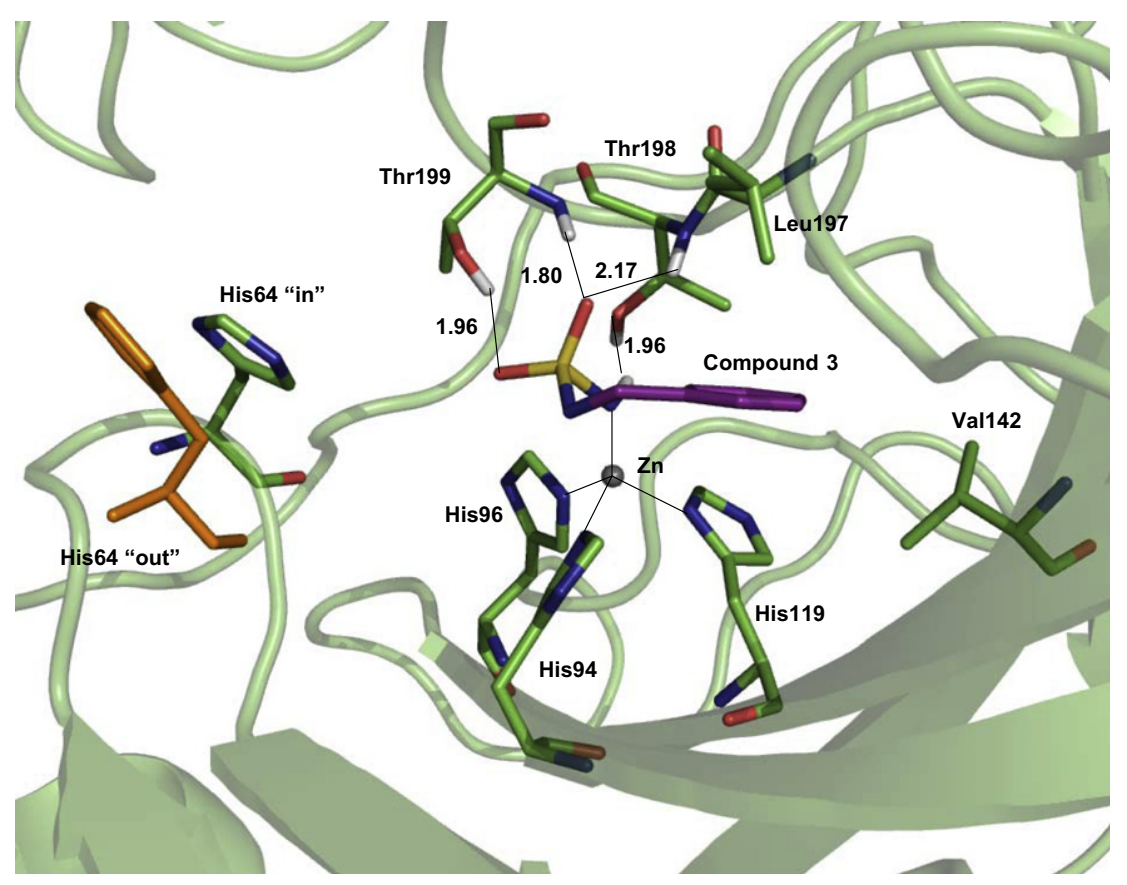

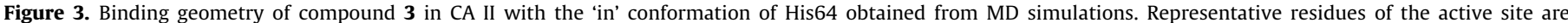

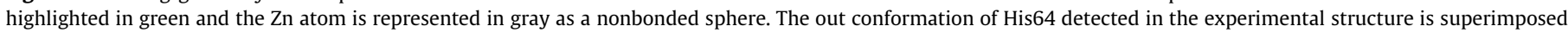

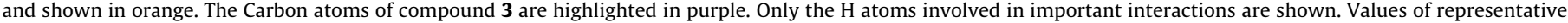
distances are given in $\AA$.

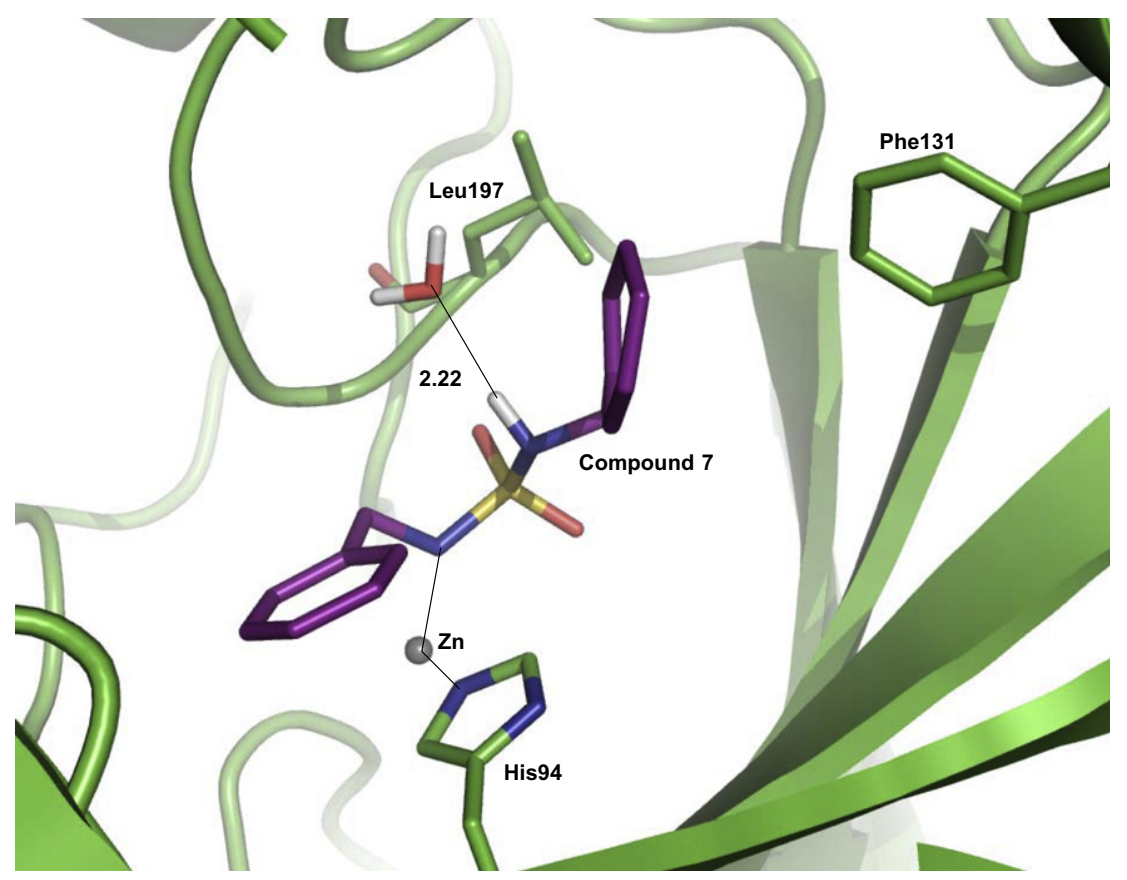

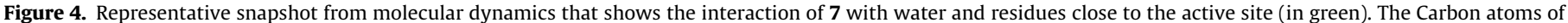
compound $\mathbf{7}$ are highlighted in purple and $\mathrm{Zn}$ atom is represented in gray as a nonbonded sphere. The value of distance to water is given in $\AA$.

compound $\mathbf{7}$ the solvent also plays a role. One water molecule acts as a donor to form a positive $\mathrm{H}$-bond interaction with the $\mathrm{H}$ atom of the non-coordinating $\mathrm{N}$ of the sulfamide function (Fig. 4).

Compound 5 also has a benzyl substituent, but it is 247 times less active than 7 and 1341 times less active than $\mathbf{3}$ in CA II. No good coordination was found for $\mathbf{5}$ in the CA II 'out' His64 conformation. For the structure of CA II 'in', the benzyl group of $\mathbf{5}$ tends to interact with the Leu197 residue in the same manner as $\mathbf{3}$, but it has to adopt a very unfavorable conformation in order to enter the active site, due to the presence of the negative steric hindrance originated by the Boc-subtituent (Fig. S3).

The docking algorithms do not explain the activity of the compounds in CA VII for either the in or the out conformation: the binding energies predicted by docking did not evidence an acceptable correlation with the biological data (Table 2). Attending the inhibitory activity, the nature of the substituent seems to be less 


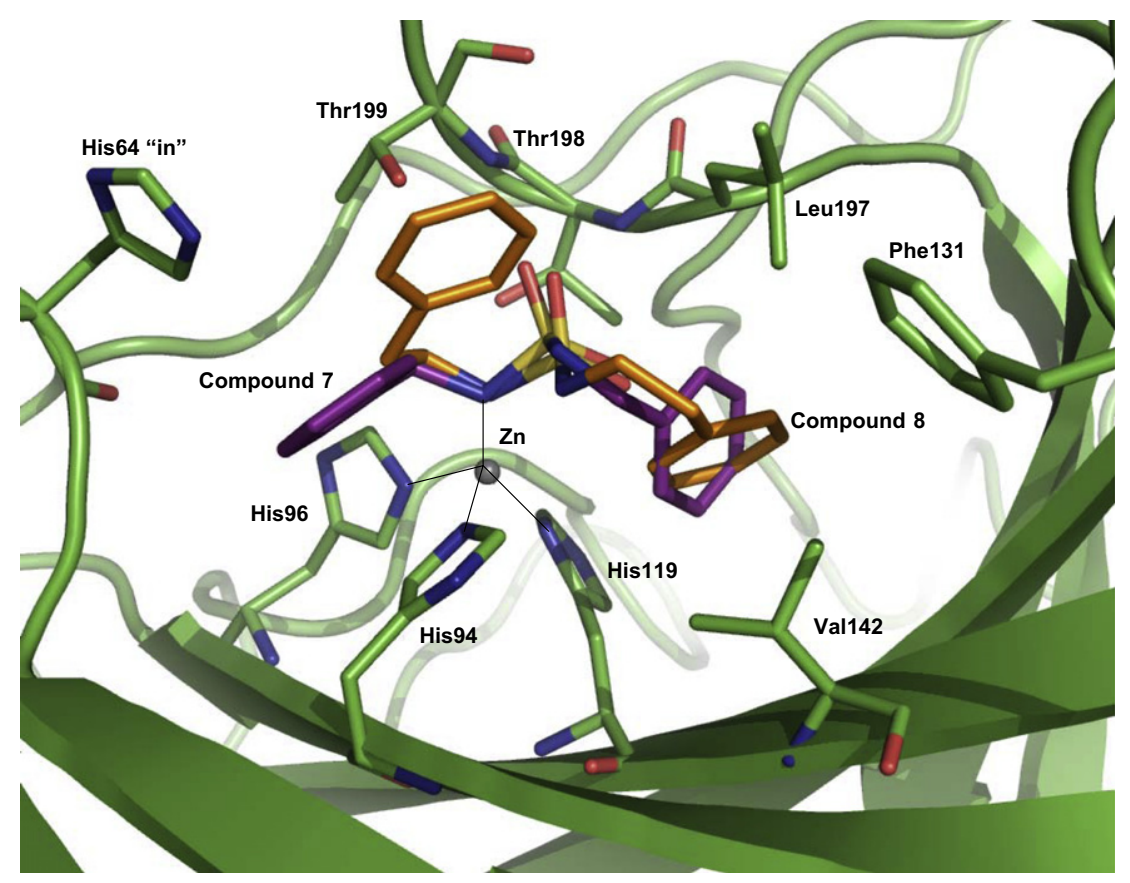

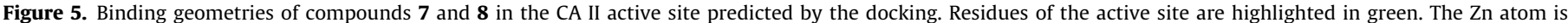
represented as a nonbonded sphere in gray. The Carbon atoms of compound $\mathbf{7}$ are highlighted in purple and those of compound $\mathbf{8}$ are highlighted in orange.
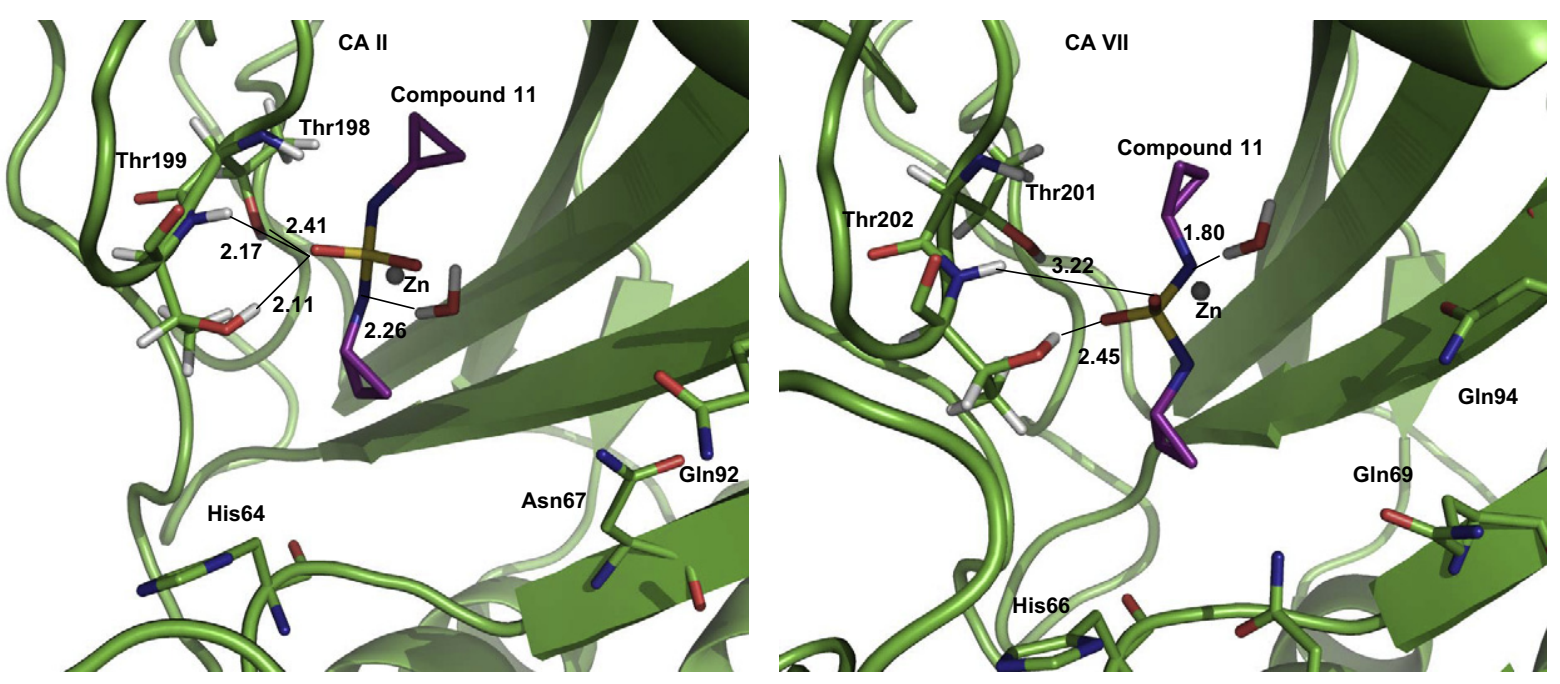

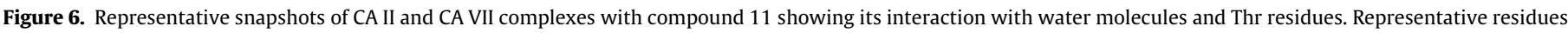

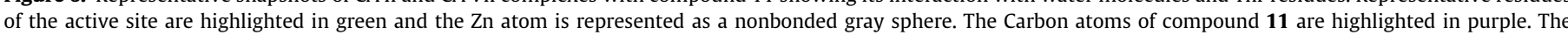
distances (in $\AA$ ) correspond to average values.

important for this isozyme: Aromatic and aliphatic compounds show similar action (compare for example compounds $\mathbf{7}$ and 9). In the same line, and contrasting with CA I and CA II, the $\mathrm{N}, \mathrm{N}^{\prime}-$ disubsitution favors the binding in some cases (compare for example $\mathbf{5}$ and $\mathbf{6}$ to $\mathbf{3}$ and $\mathbf{4}$ ). In fact, the most active compound of the set is 11, which bears two cyclopropyl rings as substituents of the sulfamide function. Moreover, a tetra-substitued ligand shows selectivity towards this isoform, which has to be associated with a different coordination mode than the one analyzed here. In order to better understand the effects that can contribute to this different trend, we run 12 ns molecular dynamic simulations of the CA VII11 complex, and CA II-11 complex, for which the ligand exerts no activity $\left(K_{\mathrm{i}}>200 \mu \mathrm{M}\right)$. We built the initial structure of the complexes using, as a template, the conformations obtained from the docking procedure.
The interactions with Thr residues previously described remained stable for both isozymes (Fig. 6). Regarding the solvation pattern, water molecules are positioned close to the active site during both MD simulations. The water $\mathrm{H}$ atom acts as donor for the $\mathrm{H}$-bond interaction with the sulfamide $\mathrm{N}$ atom that is involved in the $\mathrm{Zn}$ coordination (Fig. 6). This negative effect has been reported before for mono-substituted sulfamides, ${ }^{7}$ and it might be one of the factor that significantly diminish the activity in both isozymes.

Figure 7 shows a superposition of representative snapshots for both enzymes. The surface representation shows that the cleft that ends with the active site is more elongated in CA VII (yellow) than in CA II (red), especially in the hydrophilic region delimited by Asn64, His66, Gln69, Lys93 and Gln94 (Figure 7). Gln69 and Lys93 are distinctive residues for CA VII, and they are replaced by Asn67 and Ile91 in CA II. The larger volume available in the 


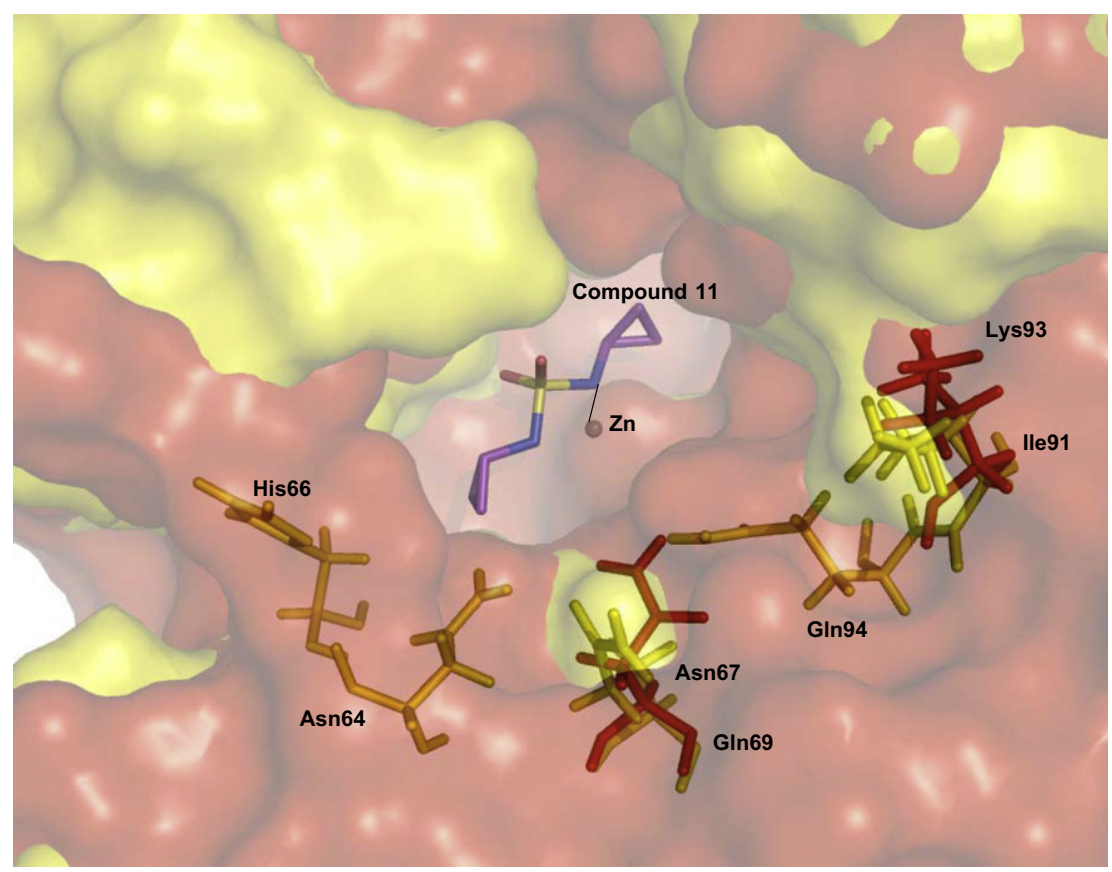

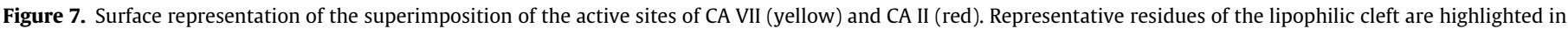

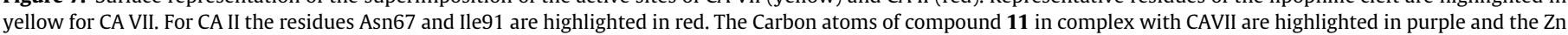
Atom is represented as a nonbonded gray sphere.

active site entrance in CA VII allows it to accommodate bulkier sulfamides interacting with the $\mathrm{Zn}$ center. This provides a possible explanation for the origin of the activity of disubsituted ligands, but does not justify the activity of compound 13. We did not further analyzed the interaction of this compound using computational techniques as we are comparing the trends for ligands that are modeled as anionic binders.

\section{Conclusions}

Sulfamides and sulfamates are the most common bioisosteres of sulfonamides, a classical zinc binding function that interacts directly with the metal $\mathrm{Zn}$ in the active site of CAs. Compounds bearing these functionalities has been proved to be potent inhibitors of several isozymes. ${ }^{1,53}$ In this investigation we provide an explanation for the different activity of sulfamides in different isozymes. To this end we applied molecular modeling techniques supported by experimental data.

We analyzed the influence of the nature of the residues close to the active site, especially the ones that are distinctive for each isozyme. We also included in the models the different orientations that can adopt the His64 residue, providing a new conformation of the CA II and CA VII active sites for further docking. We found that not all the compounds interact with the same conformation of CA II. The most active compounds interact better with the 'in' conformation of CA II whereas the 'out' conformation was preferred for other ligands. We also found that disubstitution not always impairs the inhibitory activity. The effect depends on the capability of the isozymes to accommodate the extra hydrocarbon chain (as it was shown for CA VII). This information will allow us to design more potent and isoform-selective inhibitors, with the related impact that it has in the treatment of several diseases in which the inhibition of CA is involved.

\section{Acknowledgments}

L.E. Bruno Blanch is a member of the Facultad de Ciencias Exactas, Universidad Nacional de La Plata, L. Gavernet is member of
Consejo Nacional de Investigaciones Científicas y Técnicas de la República Argentina (CONICET) and P. Palestro is a fellowship holder of CONICET. The work described herein was done in part during a Postdoctoral leave of Dr. L. Gavernet of the University of Notre Dame to whom she gratefully acknowledges. This research was supported in part by the National Science Foundation (TGCHE090124) through TeraGrid resources provided by NICS and LONI and by the Agencia de Promoción Científica y Tecnológica (PICT 01774/2010), CONICET, the Universidad Nacional de La Plata, Argentina, and the Walther Cancer Research Center, University of Notre Dame. The computations were performed on Kraken (a Cray XT5) at the National Institute for Computational Sciences (http:// www.nics.tennessee.edu/) and on Queen Bee at the Louisiana Optical Network Initiative. Generous allocation of computing resources by the Center for Research Computing at the University of Notre Dame is also acknowledged. Work from CTS lab has been financed by an European Union grant of the seventh FP programme (Metoxia project).

\section{Supplementary data}

Supplementary data (additional figures that describe the defined 'in' and 'out' conformation for CAII and CA VII, the interaction of compounds $\mathbf{7}$ and $\mathbf{8}$ in the CA VII active site and the interactions of compound $\mathbf{5}$ with CA II are given) associated with this article can be found, in the online version, at http://dx.doi.org/10.1016/ j.bmc.2012.10.048.

\section{References and notes}

1. Alterio, V.; Di Fiore, A.; D’Ambrosio, K.; Supuran, C. T.; De Simone, G. Chem. Rev. 2012, 112, 4421.

2. Supuran, C. T. Bioorg. Med. Chem. Lett. 2010, 20, 3467.

3. Supuran, C. T. In Drug Design of Zinc-Enzyme Inhibitors: Functional, Structural, and Disease Applications; Supuran, C. T., Winum, J. Y., Eds.; Wiley: Hoboken, NJ, 2009; pp 15-38.

4. Winum, J. Y.; Temperini, C.; El Cheikh, K.; Innocenti, A.; Vullo, D.; Ciattini, S.; Montero, J. L.; Scozzafava, A.; Supuran, C. T. J. Med. Chem. 2006, 49, 7024.

5. Casini, A.; Winum, J.-Y.; Montero, J.-L.; Scozzafava, A.; Supuran, C. T. Bioorg. Med. Chem. Lett. 2003, 13, 837. 
6. Winum, J. Y.; Vullo, D.; Casini, A.; Montero, J. L.; Scozzafava, A.; Supuran, C. T. J. Med. Chem. 2003, 46, 5471.

7. Gavernet, L.; Gonzalez Funes, J. L.; Bruno Blanch, L. E.; Estiu, G.; Maresca, A.; Supuran, C. T. J. Chem. Inf. Model. 2010, 50, 1113.

8. Gavernet, L.; Barrios, I.; Sella Cravero, M.; Bruno Blanch, L. Bioorg. Med. Chem. 2007, 15, 5604

9. Gavernet, L.; Elvira, J. E.; Samaja, G. A.; Pastore, V.; Cravero, M. S.; Enrique, A.; Estiu, G.; Bruno-Blanch, L. E. J. Med. Chem. 2009, 52, 1592.

10. Stringer, J. L.; Lothman, E. W. Dev. Brain Res. 1996, 91, 136.

11. Xiong, Z. Q.; Saggau, P.; Stringer, J. L. J. Neurosci. 2000, 20, 1290.

12. Bonnet, U.; Wiemann, M.; Bingmann, D. Brain Res. 1998, 796, 161.

13. Aribi, A. M.; Stringer, J. L. Epilepsy Res. 2002, 49, 143.

14. Rogawski, M. A. Epilepsy Res. 2006, 69, 273.

15. Halmi, P.; Parkkila, S.; Honkaniemi, J. Neurochem. Int. 2006, 48, 24

16. Ghandour, M. S.; Langley, O. K.; Zhu, X. L.; Waheed, A.; Sly, W. S. Proc. Natl. Acad. Sci. U.S.A. 1992, 89, 6823.

17. Ruusuvuori, E.; Li, H.; Huttu, K.; Palva, J. M.; Smirnov, S.; Rivera, C.; Kaila, K.; Voipio, J. J. Neurosci. 2004, 24, 2699.

18. Nishimori, I. In In Carbonic Anhydrase: Its Inhibitors and Activators; Supuran, C. T., Scozzafava, A., Conway, J., Eds.; CRC Press: Boca Raton, Fl, 2004; pp 25-43.

19. Hen, N.; Bialer, M.; Yagen, B.; Maresca, A.; Aggarwal, M.; Robbins, A. H.; McKenna, R.; Scozzafava, A.; Supuran, C. T. J. Med. Chem. 2011, 54, 3977.

20. Rodríguez, O. M.; Maresca, A.; Témpera, C. A.; Bravo, R. D.; Colinas, P. A.; Supuran, C. T. Bioorg. Med. Chem. Lett. 2011, 21, 4447.

21. Smainea, F. Z.; Winum, J. Y.; Montero, J. L.; Regainia, Z.; Vullo, D.; Scozzafava, A.; Supuran, C. T. Bioorg. Med. Chem. Lett. 2007, 17, 5096.

22. Casey, J. R.; Morgan, P. E.; Vullo, D.; Scozzafava, A.; Mastrolorenzo, A.; Supuran, C. T. J. Med. Chem. 2004, 47, 2337.

23. Barrios, I. A.; Rocha Arrieta, L. submitted for publication.

24. Dougherty, M.; Probs, D. A.; Robinson, R. E.; Moore, J. D.; Klein, T. A.; Snelgrove, K. A.; Hanson, P. R. Tetrahedron 2000, 56, 9781.

25. Bermann, M.; Van Wazer, J. R. Synthesis 1972, 10, 576.

26. Gong, B.; Zheng, C.; Skrzpczak-Jankun, E.; Yan, Y.; Zhang, J. J. Am. Chem. Soc. 1998, 120, 11194

27. Gong, B.; Zheng, C.; Skrzypczak-Jankun, E.; Yan, Y.; Zhang, J. J. Am. Chem. Soc. 1999, 121, 9766.

28. Vandi, A.; Moeller, T.; Audrieth, L. F. J. Org. Chem. 1961, 26, 1136.

29. Sowada, V. R. J. Prakt. Chem. 1963, 4, 310.

30. Dougherty, J. M.; Probst, D. A.; Robinson, R. E.; Moore, J. D.; Klein, T. A.; Snelgrove, K. A.; Hanson, P. R. Tetrahedron 2000, 56, 9781.

31. Winum, J.-Y.; Toupet, L.; Barragan, V.; Dewynter, G.; Montero, J.-L. Org. Lett. 2002, 3, 2241.

32. Dewynter, G.; Aouf, N.; Regainia, Z.; Montero, J.-L. Tetrahedron 1996, 52, 993.

33. Mitsunobu, O. Synthesis 1981, 1.

34. DuBois, G. E.; Stephenson, R. A. J. Org. Chem. 1980, 45, 5371.

35. DuBois, G. E. J. Org. Chem. 1980, 45, 5373.

36. Appel, R.; Berger, G. Chem. Ber. 1958, 91, 1339

37. Khalifah, R. G. J. Biol. Chem. 1971, 246, 2561.

38. Vullo, D.; Nishimori, I.; Scozzafava, A.; Köhler, S.; Winum, J. Y.; Supuran, C. T. Bioorg. Med. Chem. Lett. 2010, 20, 2178.
39. Kolayli, S.; Karahalil, F.; Sahin, H.; Dincer, B.; Supuran, C. T. J. Enzyme Inhib. Med. Chem. 2011, 26, 895.

40. Maresca, A.; Vullo, D.; Scozzafava, A.; Supuran, C.T. J. Enzyme Inhib. Med. Chem http://dx.doi.org/10.3109/14756366.2011.649268.

41. Morris, G. M.; Goodsell, D. S.; Halliday, R. S.; Huey, R.; Hart, W. E.; Belew, R. K.; Olson, A. J. J. Comput. Chem. 1998, 1639.

42. Srivastava, D. K.; Jude, K. M.; Banerjee, A. L.; Haldar, M.; Manokaran, S.; Kooren, J.; Mallik, S.; Christianson, D. W. J. Am. Chem. Soc. 2007, 129, 5528.

43. Jude, K. M.; Banerjee, A. L.; Haldar, M. K.; Manokaran, S.; Roy, B.; Mallik, S.; Srivastava, D. K.; Christianson, D. W. J. J. Am. Chem. Soc. 2006, 128, 3011.

44. Fisher, Z.; Prada, J. A. H.; Tu, C.; Duda, D.; Yoshioka, C.; An, H. Q.; Govindasamy, L.; Silverman, D. N.; McKenna, R. Biochemistry 2005, 44, 1097.

45. Ugochukwu, E.; Shafqat, N.; Pilka, E.; Chaikuad, A.; Krojer, T.; Muniz, J.; Kim, J.; Bray, J.; Bountra, C.; Arrowsmith, C.H.; Weigelt, J.; Edwards, A.; von Delft, F.; Carpenter, E.P.; Yue, W.W.; Oppermann, U. to be published.

46. Case, D. A.; Darden, T. A.; Cheatham, T. E., III; Simmerling, C. L.; Wang, J.; Duke R. E.; Luo, R.; Walker, R. C.; Zhang, W.; Merz, K. M.; Roberts, B.; Wang, B.; Hayik, S.; Roitberg, A.; Seabra, G.; Kolossváry, I.; Wong, K. F.; Paesani, F.; Vanicek, J.; Liu, J.; Wu, X.; Brozell, S. R.; Steinbrecher, T.; Gohlke, H.; Cai, Q.; Ye, X.; Wang, J.; Hsieh, M.-J.; Cui, G.; Roe, D. R.; Mathews, D. H.; Seetin, M. G.; Sagui, C.; Babin, V.; Luchko, T.; Gusarov, S.; Kovalenko, A.; Kollman, P. A. AMBER 11; University of California: San Francisco, 2010.

47. Quality Atomic Charges, Proton Assignment and Canonicalization, QuACPAC OpenEye Scientific Software, Inc.: Santa Fe, NM, 2007

48. Wang, J.; Wolf, R. M.; Caldwell, J. W.; Kollman, P. A.; Case, D. A. J. Comput. Chem 2004, 25, 1157.

49. Bayly, C. A.; Cieplak, P.; Cornell, W. D.; Kollman, P. A. J. Phys. Chem. 1993, 97, 10269.

50. Fox, T.; Kollman, P. A. J. Phys. Chem. B 1998, 102, 8070.

51. Becke, A. D.; Yarkony, D. R. In Modern Electronic Structure Theory Part II; World Scientific: Singapore, 1995.

52. Frisch, M. J.; Trucks, G. W.; Schlegel, H. B.; Scuseria, G. E.; Robb, M. A.; Cheeseman, J. R.; Montgomery, J. A., Jr.; Vreven, T.; Kudin, K. N.; Burant, J. C. Millam, J. M.; Iyengar, S. S.; Tomasi, J.; Barone, V.; Mennucci, B.; Cossi, M.; Scalmani, G.; Rega, N.; Petersson, G. A.; Nakatsuji, H.; Hada, M.; Ehara, M.; Toyota, K.; Fukuda, R.; Hasegawa, J.; Ishida, M.; Nakajima, T.; Honda, Y.; Kitao, O.; Nakai, H.; Klene, M.; Li, X.; Knox, J. E.; Hratchian, H. P.; Cross, J. B. Bakken, V.; Adamo, C.; Jaramillo, J.; Gomperts, R.; Stratmann, R. E.; Yazyev, O.; Austin, A. J.; Cammi, R.; Pomelli, C.; Ochterski, J. W.; Ayala, P. Y.; Morokuma, K.; Voth, G. A.; Salvador, P.; Dannenberg, J. J.; Zakrzewski, V. G.; Dapprich, S.; Daniels, A. D.; Strain, M. C.; Farkas, O.; Malick, D. K.; Rabuck, A. D. Raghavachari, K.; Foresman, J. B.; Ortiz, J. V.; Cui, Q.; Baboul, A. G.; Clifford, S.; Cioslowski, J.; Stefanov, B. B.; Liu, G.; Liashenko, A.; Piskorz, P.; Komaromi, I.; Martin, R. L.; Fox, D. J.; Keith, T.; Al-Laham, M. A.; Peng, C. Y.; Nanayakkara, A. Challacombe, M.; Gill, P. M. W.; Johnson, B.; Chen, W.; Wong, M. W.; Gonzalez, C.; Pople, J. A. Gaussian 03, revision C.02; Gaussian, Inc.: Wallingford, CT, 2004.

53. Gitto, R.; Damiano, F. M.; Mader, P.; De Luca, L.; Ferro, S.; Supuran, C. T.; Vullo, D.; Brynda, J.; Rezacova, P.; Chimirri, A. J. Med. Chem. 2011, 55, 3891. 